\title{
FORMACIÓN DE PROFESORES, CURRÍCULO E INFANCIA EN COMUNIDADES TRADICIONALES EN LA AMAZONIA
}

\section{TEACHER TRAINING, CURRICULUM AND CHILDHOOD IN TRADITIONAL COMMUNITIES IN THE AMAZON}

\author{
Fabiola Aparecida F. Damacena ${ }^{1}$ - Raquel Lopes $^{2}$
}

Fecha de recepción: 12-04-2021

Fecha de aceptación y versión final: 24-08-2021

\section{Resumen}

Este trabajo discute la posibilidad de implementar una nueva política de atención educacional a la infancia rural por medio de cambios en el currículo de los cursos de formación docente. Así pues, su principal objetivo es presentar evidencias para establecer cambios paradigmáticos en la matriz sociopedagógica de los procesos formativos de los futuros docentes. Se señalan aspectos de una experiencia concreta realizada entre los años 2015 y 2019 en el interior de la Amazonia brasileña, más específicamente en el suroeste paraense. La metodología de análisis que se ha utilizado se afianza en la investigación narrativa por tratarse de un relato de experiencia en la formación de docentes en los procesos de desarrollo profesional relacionados con la infancia. Se trata de un estudio cualitativo por considerar el análisis de los datos, la subjetividad y la participación del investigador como parte de la experiencia relatada. Los resultados más importantes indican la urgente necesidad de invertir la lógica de la formación docente para superar la perspectiva abstracta basada en supuestos universalizantes y colonizadores, como también aproximar los fundamentos de los procesos formativos a las características del territorio de su efectivización y de los sujetos que allí están implicados, teniendo en cuenta prioritariamente a los infantes a los que se va a atender. En esa dirección, el diálogo con los datos lleva a la conclusión ineludible de que es urgente fundamentar el currículo de los cursos de formación docente en ejes estructurantes ligados a la práctica pedagógica, a la diversidad sociocultural y a los derechos humanos.

Palabras clave: Formación docente - Educación infantil - Currículo - Magisterio ExtractivistaDescolonización.

\section{Abstract}

This paper discusses the possibility of implementing a new educational assistance policy for rural children through changes in the curriculum of teacher education courses. Thus, its main objective is to present evidence in order to enable paradigmatic changes in the sociopedagogical matrix of the educational processes of the future teachers, highlighting some aspects of a particular experience carried out between the years of 2015 and 2019 in the countryside of Brazilian Amazon, more specifically in the Southwest of Pará. The methodology used is characterized by the direct immersion in the context of the experience registered in this work as well as by participant observation and the reflection of records resulting from it. The most important results indicate an urgent need to reverse the logic of teacher education overcoming an abstract perspective based on universalized and colonizing assumptions as well

\footnotetext{
${ }^{1}$ Profesora de la Universidad Federal de Pará-Facultad de Etnodiversidad. Brasil. Doctoranda en educación en la Universidad Estadual de Campinas-UNICAMP. Correo electrónico: fabiferreira@ufpa.br ${ }^{2}$ Profesora de la Universidad Federal de Pará en la Facultad de Etnodiversidad. Brasil. Correo electrónico: ralopes@ufpa.br
} 
RIIE (2021), Año 12 (16), 51- 68.

DOI: http://dx.doi.org/10.30972/riie.13165757

as to bring the fundamentals of educational processes closer to the characteristics of the territory where they will be applied together with the involved subjects, with a view to prioritize the childhood to be assisted. In this sense, the dialogue with data leads to the unavoidable conclusion that it is urgent to base the curriculum of teacher educational courses on structural axes linked to pedagogical practice, sociocultural diversity and human rights (i).

Key words: Teacher Education - Child education - Curriculum - Extractive Teaching Decolonization. 


\section{Introducción}

Al tomar la infancia como lugar de partida y de llegada, podemos discutir metodologías, contenidos, evaluación del aprendizaje a partir de otros referenciales sean ellos de matriz tecnológica, positivista, colonizadora, pero siempre tomando a los niños y a las niñas como sujetos de conocimiento y como foco de investigación académica, con vistas a la producción de datos que subsidien a los currículos de los cursos de formación de docentes, así como también para la elaboración de políticas públicas y de legislación referente a la Educación Infantil y a la infancia, en el centro de tensiones y conflictos, relaciones de poder, presiones externas a la escuela y negociaciones constantes en el campo educacional.

Pensar la infancia en una perspectiva crítica implica deconstruir la concepción normativa de esa categoría social, del sesgo de la universalidad y de carácter etnocéntrico que marca la visión sobre los derechos de los niños y las niñas. Implica problematizar las desigualdades que permean el campo de la aplicación de esa prerrogativa, sobre todo en lo que respecta a la cuestión del derecho a la educación en áreas de conservación en la Amazonia. Aunque existe una amplia e intensa discusión sobre los derechos de los niños y de las niñas, tenemos hoy escenarios muy complejos, afectados por la globalización de cuño neoliberal, que se extienden más allá de sus límites.

El derecho formal, normatizado por decretos, pareceres y resoluciones en mayor o menor grado de implementación, aún no se ha materializado en un cuadro operacional y simbólico que mejore, de hecho, las condiciones de vida de los niños y de las niñas, que les garantice acceder a sus derechos como tales y al reconocimiento como sujetos sociales.

La metodología de análisis que se ha utilizado se afianza en la investigación narrativa por tratarse de un relato de experiencia en la formación de docentes en los procesos de desarrollo profesional relacionados con la infancia. Se trata de un estudio cualitativo por considerar el análisis de los datos, la subjetividad y la participación del investigador como parte de la experiencia relatada. Clandinin y Connelly (2015) resaltan que "cuando los investigadores narrativos están en campo, nunca están allí como mentes (sin cuerpo) registradoras de la experiencia de alguien. Ellos también están viviendo una experiencia". (p. 120)

De esta manera, esperamos mostrarles en este artículo como el contexto de la educación infantil puede ser un lugar para efectivizar esas prerrogativas, mediante la narrativa de prácticas pedagógicas insumisas, que provoquen fisuras en la dureza de la realidad para inventar horizontes de transformación, incluso como forma de resistencia y denuncia contra la negligencia del Estado en promover y garantizar los derechos de los niños y de las niñas.

En consonancia con el pensamiento de Sarmento y Tomás (2020), buscamos presentar prácticas educativas a partir de un proceso de formación de profesores que teniendo presente la infancia y la concepción de los derechos de los niños y de las niñas en su diversidad y amplitud a partir de las interseccionalidades entre condición generacional, clase, género, etnia, en una dinámica que pueda garantizar que todas los niños y las niñas tengan acceso a una educación en sus contextos, territorios, atinente a sus identidades de sujetos culturales pues "hay una voluntad generalizada de las naciones hacia la construcción de una sociedad más democrática e inclusiva, 
alineada con los Derechos Humanos, siendo la participación cívica un medio y un fin para que eso suceda". (Barbosa, 2013, p. 70)

Queremos construir una escuela que oiga las voces y las experiencias de los niños y de las niñas, y que en sus espacios educativos se produzcan colectivamente enseñanzas y conocimientos que interactúen con la creatividad, con la cultura, involucrando de hecho el contexto de la comunidad escolar y su entorno. De este modo los niños y las niñas deben ejercer su papel de protagonistas en la transformación de sus condiciones de existencia, aún con todas las contradicciones estructurales que sustentan los procesos de dominación en la sociedad que vivimos.

Al asumir este desafío, elegimos caminos críticos a partir de los lugares que ocupamos y de las formas de producir y validar conocimientos, tensionando el campo de la formación de docentes, con sus currículos prescritos y descontextualizados; optamos por un quehacer pedagógico de(s)colonial, haciendo el ejercicio de desatar los nudos opresores de la colonización cognitiva, hablando desde el lugar de donde hemos venido, de las experiencias que traemos, en la búsqueda de una educación como práctica de libertad (Freire, 1967), pautada por una forma sensible de escuchar al otro y por la posibilidad de reinvención del futuro. Esperamos que la experiencia que les presentamos aquí lo evidencie.

\section{Por un nuevo paradigma en la formación de docentes: educación fundada en la diversidad pretendiendo la emancipación de todos los sujetos}

En este trabajo traemos a la luz algunas evidencias de la posibilidad concreta de implementar una política de formación docente fundamentada en el urgente compromiso con la universalización del acceso a la educación escolar como estrategia de lucha política de pueblos y comunidades tradicionales en la brega por derechos, especialmente con relación a las infancias. En ese sentido, trazamos observaciones político-filosóficas a partir de una experiencia que será dilucidada enseguida, en el intento de evidenciar que es posible pensar una nueva matriz de formación docente, orientada por procesos de intercambios entre diferentes sujetos colectivos, conocimientos plurales y prácticas culturales diversas en una perspectiva dialógica y emancipadora, pautada en la alegría, esperanza, aprehensión de la realidad y convicción de que un cambio es posible (Candau, 2011; Freire, 1996).

Ese esfuerzo de pensar y realizar experiencias de formación de docentes a contramano del paradigma hegemónico que hoy prevalece en la mayoría absoluta de las instituciones/agencias de formación, y aún muy enraizado en el imaginario social, se justifica por la necesidad de democratizar el acceso a la educación escolar como derecho humano fundamental, no sólo en el plano formal (en la letra de la ley), sino, especialmente, en el plano de la vida práctica, de lo cotidiano de centenas de niños, niñas, jóvenes y adultos que aún se encuentran al margen de cualquier sistema de enseñanza oficial - especialmente los que viven en lugares aislados y remotos.

Resaltamos que no concebimos la educación escolar desde un sesgo redentorista marcado por ingenuidad política o filosófica, visión que produce y sustenta acciones aisladas de carácter salvacionista y según la cual basta ser escolarizado para "ser ciudadano", pues, como nos recuerda A. Freitas,

En ese contexto, afirmar simplemente que la función social de la escuela consiste en "formar para la ciudadanía", sin tener en consideración los Revista del Instituto de Investigaciones en Educación

ISSN $1853-1393$

Resistencia, Chaco. Argentina 
límites de la propia educación, es proponer un "discurso vacío" desconectado de los asuntos que involucran la construcción de los vínculos sociales y de sus impactos en la formación de la identidad y de la ciudadanía democrática. (Freitas, 2007, p. 11)

Sin embargo, somos conscientes de la importancia estratégica de la educación escolar como "derecho agregador" (Arroyo, 2017) porque, dependiendo de las variables que se tengan en consideración, particularmente vincular el carácter emancipador de la propuesta pedagógica a los intereses de los sujetos implicados, la educación se reviste de potencial de transformación y puede actuar, resalta Miguel Arroyo, como una especie de vanguardia en la lucha política por otros derechos sociales, amplificando y catalizando acciones colectivas locales, aunque sea en microescalas.

Reconocemos que la situación en que se encuentra la educación escolar entre nosotros tiene raíces históricas profundas y es de gran complejidad estructural y política. Al final, desde la llegada de los europeos, se ha impuesto una matriz pedagógica de fuerte cuño colonizador que conformó nuestra tradición escolar de forma indeleble y cuyas consecuencias nefastas se hacen sentir aún hoy (recordemos, entre otros hechos, un rasgo de la reforma implementada por el Marqués de Pombal en 1757 al criminalizar el uso de cualquier otra lengua que no fuera el portugués metropolitano).

No obstante, existe este conjunto de imposiciones que intimidan a la escuela, como institución y como espacio de sociabilidad en el cual se producen identidades, insistimos en la necesidad de repensar la naturaleza de la acción educativa 'por dentro', someter a escrutinio sus fundamentos, poner en cuestión sus tradiciones y reinventar nuestras prácticas. Del punto de vista teórico, el propósito, en sí, no es nuevo y viene siendo objeto de debate en diferentes campos de las ciencias humanas en los últimos años, en diferentes direcciones, de acuerdo con diferentes opciones teóricas (cf. Alarcão, 1998; Alonso, 1999; Nóvoa, 1995; 1999; Perrenoud, 2000; 2005; Saviani, 2009; Gatti, 2010; Pinho; Lopes, 2016, entre otros).

Por tanto, nos gustaría avanzar, no solo en la crítica de naturaleza teórica, puesto que se hicieron innumerables esfuerzos de comprensión y que los fundamentos de una nueva matriz epistemológica se han delineado, con mayor o menor repercusión junto a las agencias de formación docente y, usualmente, con poco o ningún efecto práctico en el ámbito de la sala de clase de la educación básica donde tales proposiciones se deberían hacer sentir. Lo que nos parece relevante está relacionado, justamente, a la posibilidad de localizar, a partir de un caso concreto (el Proyecto de Formación de Maestros Extractivistas de Terra do Meio/Magisterio, que será presentado en la próxima sección), indicadores que permitan mensurar la viabilidad, o la operacionalización, de una acción político-pedagógica contra hegemónica en el campo de la formación docente y que, esperamos, pueda servir de evidencia exitosa y de semilla para otras iniciativas en contextos similares.

Tratándose de comunidades amazónicas dispersas a lo largo de ríos y bosques, tenemos un doble desafío: garantizar el acceso a la escuela pública (que ya está supuestamente garantizado a otros segmentos de la sociedad) y luchar para que la atención escolar no sea una mera repetición de la tragedia social y humana marcada por el sesgo asimilacionista, colonizador y fuertemente urbano céntrico que caracteriza a la escuela como institución desde sus primeras incursiones en el 
territorio brasileño, sesgo que hasta el hartazgo ha sido denunciado por las comunidades campesinas, indígenas, quilombolas y extractivistas en el extranjero.

Ha sido precisamente la percepción que esos segmentos sociales advirtieron sobre el desajuste existente entre la educación escolar que les ha sido/es ofrecida y sus proyectos de vida y de futuro, lo que los ha movilizado hacia la lucha de otros paradigmas de educación escolar, llevándolos no solo a reivindicar, sino también a pensar y proponer "otras pedagogías" (Arroyo, 2012). Así, se fueron constituyendo, a lo largo de las décadas de 1990 y 2000, con el impulso de la promulgación de la Constitución Federal de 1988, diversos movimientos socio-educacionales que contribuyeron para la proposición de nuevos parámetros políticos y reglamentarios en la educación escolar brasileña: la Ley de Directrices y Bases de la Educación Nacional, en 1996; y, más tarde, las diversas directrices curriculares específicas, como las de la educación escolar indígena en 1999 (Parecer CNE/CEB nº 14/1999), las de la educación del campo (Parecer CNE/CEB № 36, del 4 de diciembre de 2001) y las de la educación escolar quilombola (Parecer CNE/CEB nำ16/2012, aprobado el 5 de junio de 2012).

A pesar de los considerables avances teóricos y legislativos, en el plano de llevar a cabo la implementación de las políticas públicas, permanecieron inalterados numerosos factores profundamente problemáticos al ofrecer la educación escolar a las comunidades que han sido mencionadas. Entre los factores, se destaca la actuación de los maestros, que, en la mayor parte de los casos, no tenían formación o si la tenían no estaba acorde con la necesidad de los estudiantes ni con la de sus territorios.

Se consolidan así las demandas por procesos de formación docente ajustados a las necesidades y aspiraciones de las comunidades socioculturalmente diversas. El Decreto o 6.755, del 29 de enero de 2009, constituye una referencia importante que va hacia esa dirección, al instituir la Política Nacional de Formación de Profesionales del Magisterio de la Educación Básica disciplinando la actuación de la Coordinación de Perfeccionamiento de Personal de Nivel Superior/CAPES en el fomento de programas de formación inicial y continua. En su Art. 11, determina que esa agencia también fomentará:

I- proyectos pedagógicos que tengan por objetivo promover nuevos diseños curriculares o recorridos formativos destinados a los profesionales de magisterio;

II- proyectos pedagógicos que tengan por objetivo promover diseños curriculares propios a la formación de profesionales de magisterio para atender a la educación del campo, de los pueblos indígenas y de comunidades remanentes de los quilombos; [...]

Anteriormente, se habían implementado algunos proyectos de formación docente que estaban dirigidos a comunidades específicas, como el Curso de Licenciatura Intercultural, para la formación de maestros/profesores indígenas, y el Curso de Licenciatura en Educación del Campo para maestros /profesores ligados a las comunidades campesinas; y así, por medio del decreto referido es que se reconoce oficialmente esa necesidad, que pasa a ser objeto de una serie de políticas fomentadas en el interior del Ministerio de Educación, como PROLIND/Programa de Apoyo a la Formación Superior y Licenciaturas Indígenas y PROCAMPO/Programa de Apoyo a la Formación Superior en Licenciatura en Educación del Campo. 
Esa estructura legal/oficial produce nuevas dinámicas en la política de atención a las demandas por tener educación diferenciada, ofreciendo orientaciones legales significativas a los movimientos de lucha por el derecho a la educación al preconizar atribuciones al Estado en lo que respecta a la elaboración e implementación de acciones y programas educacionales para los diferentes sujetos colectivos del campo, apuntando nuevos rumbos en cuanto a la garantía de universalización del derecho a la educación, con valorización e inclusión de prácticas escolares diferenciadas.

Pero, si para buena parte del país, se trataba de demandar formación docente de nivel superior para mejorar la calidad de la oferta de educación básica en el campo, como preconiza la LDB de 1996, en la Amazonia aún había muchas comunidades donde la presencia del estado era tan escasa, pero tan escasa, que ni siquiera había escuela de "primeras letras", como en Terra do Meio, en la confluencia de los ríos Xingu e Iriri, en el suroeste del estado de Pará - territorio habitado por pueblos indígenas y por extractivistas descendientes de los trabajadores del ciclo del caucho. Es sobre una experiencia de formación docente diferenciada con extractivistas, de nivel medio, que tratamos en este trabajo, con un recorte volcado hacia la docencia en la educación infantil.

\section{El contexto de la experiencia - El Proyecto Magisterio Extractivista de Terra do Meio}

El Proyecto de Formación de Docentes, en el ámbito que se sitúa la experiencia tratada en este trabajo, se incluye en el flujo de acciones ligadas a políticas, proyectos y programas de atención a las demandas de pueblos y comunidades tradicionales facultados por la publicación del ya mencionado Decreto oㅜ 6.755 , del 29 de enero de 2009. Antes de entrar en la información específica de este Proyecto, presentaremos de forma breve algunos datos sobre el territorio en el que fue implementado - Terra do Meio.

Con ese nombre, Terra do Meio, nos referimos a un territorio en el interior de la Amazonia brasileña que representa cerca del $6 \%$ del estado de Pará, abarcando un $38,62 \%$ del municipio de Altamira, 19,25\% del municipio de São Félix do Xingu, además de una pequeña parte del municipio de Trairão. Es una región remota, con baja densidad poblacional, pero de gran importancia socio-ambiental. Durante casi un siglo fue escenario de disputas entre los pueblos indígenas y los forasteros debido a los ricos recursos, especialmente el látex; además del ciclo del caucho, pasó por los ciclos de la castaña, del oro y de la retirada de piel de panteras y jaguares para la exportación en la década de 1970 (cf. Velásquez et al., 2006).

Después del declive de esos ciclos económicos, la población residente en ese territorio vivía en relativo aislamiento y eran invisibles al resto de la sociedad brasileña, sufriendo intentos de saqueos de sus tierras por parte de personas malintencionadas con documentos falsos (grileiros en portugués), hacendados y explotadores de madera de ley. A partir de los años 2000, empiezan a organizarse y, con apoyo de los movimientos sociales, se comienza un proceso de reconocimiento que va a culminar, años más tarde, con un decreto que crea un inmenso corredor de biodiversidad (Brasil, 2000). En el año 2004, empezaron a crearse unidades de conservación, algunas de protección integral (Parque Nacional da Serra do Pardo y Estación Ecológica del Río 
Iriri) y otras de uso sustentable, como las Reservas Extractivistas (Resex Riozinho do Anfrísio, Resex Rio Iriri, Resex Rio Xingu).

El Sistema Nacional de Unidades de Conservación - SNUC (Brasil, 2000) define Reservas Extractivistas como espacios territoriales destinados a la conservación de los modos de vida de las poblaciones tradicionales en consonancia con el uso sustentable de los recursos naturales. Para orientar el alcance de ese fin, cada unidad de conservación (UC) tiene un marco regulador, su Plan de Manejo, que es un acuerdo formal de convivencia entre la población residente, la sociedad del entorno y el Estado brasileño; este documento, por lo menos en términos ideales, debe ser el resultado de una consulta informada al conjunto de los habitantes de determinada área protegida.

Esas comunidades viven del extractivismo, del intercambio y comercialización de productos naturales y artesanales, además de actividades basadas en la pesca, en la agricultura y en la cría de pequeños animales. Su modo de vida, en equilibrio con la naturaleza, es una forma de contribución a la preservación de la biodiversidad; pero, a pesar de su importancia socio ambiental, se encuentran en una situación de descuido y abandono tan grande que hasta el momento de reconocimiento de este territorio como área de protección, cerca del $90 \%$ de los pobladores no tenía cédula de identidad, tampoco el registro de persona física/CPF, ni el documento de elector o cualquier otro tipo de documento de identificación. El índice de analfabetismo era de casi el $100 \%$.

Las primeras escuelas empezaron a funcionar solamente en 2008, de manera multiseriada atendiendo de $1^{\circ}$ a $5^{\circ}$ año de la enseñanza primaria, pero sin un proyecto político-pedagógico adecuado y sin una política consistente de atención a la demanda escolar de las comunidades; faltaban escuelas en la mayoría de las localidades, en las existentes la infraestructura era bastante precaria y no existía plan de carrera para los profesionales que trabajan allí.

Por haberla implementado sin estudiar previamente las características socioantropológicas de la población a la que se iba a atender, la educación escolar ofrecida por la Secretaría Municipal de Educación generó una serie de conflictos, creando nuevos problemas a las comunidades y no garantizó los resultados esperados en cuanto a la escolarización de los niños, de las niñas y de los jóvenes. Este desajuste entre la atención escolar y las necesidades locales motivó una serie de quejas de las familias junto a la propia Secretaría de Educación y también junto a otras instituciones, como el Ministerio Público Federal, el Instituto de Conservación de la Biodiversidad, entre otras.

Fue en este contexto que, en mayo de 2011, llegó a la Universidad Federal de Pará/Campus de Altamira el pedido que habían hecho esas comunidades extractivistas buscando otro modelo de educación escolar, una educación que las tomara como sujetos de derecho, con su historia, cultura, necesidades y aspiraciones propias, y no solo como "clientes" de paquetes educacionales elaborados a su capricho, trasplantados de áreas urbanas y sin ninguna conexión con su territorio, con sus temporalidades e inquietudes.

En respuesta a ese pedido y en estrecha relación con líderes comunitarios, representantes de las comunidades y de instituciones que actuaban en Terra do Meio (FVPP, ICMBio, ISA, MPF, entre otras), un grupo de profesores investigadores de la Universidad Federal de Pará/Campus de Altamira, formado por Alcione Meneses, 
Flávio Barros, Francilene Parente y Raquel Lopes, asumió el compromiso de realizar un estudio para investigar la situación de la educación escolar en las tres Reservas Extractivistas de Terra do Meio (Resex Rio Xingu, Resex Riozinho do Anfrísio y Resex Rio Iriri (por más detalles, ver Lopes et al, 2013).

Los resultados de este estudio revelaron que la formación de maestros/profesores locales es la única alternativa viable para garantizar una escolarización de calidad para los habitantes de esas áreas, ya que la educación que había sido ofrecida hasta ese momento no atendía a sus necesidades, además de sufrir constantes discontinuidades, y fragilizar el tejido social local "... empujando a muchos jóvenes hacia la ciudad en condiciones de inseguridad social, emocional y financiera". (UFPA, 2014, p. 05)

Así, y en consonancia con las comunidades interesadas, los investigadores de la Universidad Federal de Pará/Campus de Altamira, elaboraron una propuesta de curso de formación de maestros/profesores locales con la intención de habilitar profesionales para atender la demanda escolar existente, formando sujetos capaces de protagonizar una ruptura con el modelo de escuela que les causaba desagrado, asumiendo prácticas docentes diferenciadas y conectadas con las necesidades de los pobladores locales, sin que tuvieran que ausentarse de sus territorios. Esa formación tendría que darse también en nivel medio, dada la inexistencia de personas con certificado escolar acorde con el ingreso al nivel superior.

La LDB de 1996, en su Título VI - De los Profesionales de Educación, estableció que para actuar en la educación básica los docentes deben estar formados en el nivel superior, en curso de docencia, de graduación plena (el país tendría diez años para garantizar esa formación a sus docentes), pero dejó abierta la posibilidad de que se acepte la formación mínima en el nivel medio para actuar en la educación infantil y en los años iniciales de la enseñanza fundamental, con la condición de que fuera implementada una política de elevación de la escolarización de estos profesionales (formación en servicio). Veamos. En su Art. 61, se consideran profesionales de la educación escolar básica los que están en efectivo ejercicio y que se han formado en cursos reconocidos.

El Art. 61 de la referida Ley de Directrices y Bases de la Educación fue alterado por la Ley no 12.014, del 6 de agosto de 2009; así, se pasó a considerar profesionales de la educación escolar básica a los que están en efectivo ejercicio y están formados en cursos reconocidos. En el inciso I, se prevé que los profesores/maestros son profesionales "habilitados en nivel medio o superior para la docencia en la educación infantil y en la enseñanza fundamental y media". (s/n)

Considerando la posibilidad de que la formación en el nivel medio sea aceptada como requisito mínimo para la actuación docente en la educación infantil y en los años iniciales de la educación básica, y teniendo en cuenta el hecho de que hasta hace muy poco tiempo no existían escuelas en las Resex de Terra do Meio, por tanto no había sujetos de esa localidad con escolarización suficiente para ingresar en un curso de nivel superior, en la proposición de un curso de formación docente para atender la demanda local tuvo que ser ponderada la necesidad de elevar la escolaridad de los futuros maestros/profesores desde la enseñanza fundamental.

Así, el Proyecto Magisterio Extractivista fue diseñado para que suceda en un periodo de cuatro años (2015-2019), el primero, fue reservado para elevar y concluir la enseñanza fundamental; en los tres años siguientes, se daba la formación técnica en 
Magisterio integrada a la enseñanza media. Según el texto de la propuesta de este proyecto, inspirado en una pedagogía contra hegemónica, fue su objetivo formar docentes extractivistas a partir de una perspectiva asentada en la idea de territorio, con:

... fundamentación teórico-práctica consistente para ejercer la docencia en la educación infantil y en los años iniciales de la enseñanza fundamental, con la profundización de estudios y de reflexión crítica frente a la realidad de su futura actuación, sin dejar de lado los conocimientos volcados a la educación general. (UFPA, 2014 p. 08)

Para alcanzar este intento, se asumió como eje estructurante la Pedagogía de Alternancia (Gimonet, 2007; Parente, Lopes y Miléo, 2020) teniendo en consideración las peculiaridades geográficas de las comunidades, las cuestiones socioantropológicas de la población y las inquietudes de las familias en cuanto a la escolarización de sus hijos. Al asumir parámetros político-filosóficos emancipadores y colectivos, la Pedagogía de Alternancia se concretiza como sistema educativo antagónico al proyecto educacional validado por la modernidad. El principio de la alternancia, comprendido como una práctica sociopolítica capaz de articular diferentes tiempos y espacios de aprendizajes - tiempo escuela (TE) y tiempo comunidad (TC), moviliza saberes tradicionales comunitarios y los relaciona a los saberes escolares en una concepción horizontal y dialéctica (Gimonet, 2007).

\section{Narrativa pedagógica del proceso de formación de profesores para la infancia}

Al mirar con profundidad las experiencias que en diversos espacios se elaboran con la infancia, se nos llama a pensar en modos de organización de un trabajo de intercambio en la relación con ella, a partir de una temporalidad que le es propia, orientada por la perspectiva decolonial, intergeneracional y que va en el sentido de construir prácticas pedagógicas productoras de subjetividades emancipadoras de los sujetos en sus espacios de resistencia.

Aprendimos a construir esa mirada a partir de la potencia del encuentro proporcionado por las experiencias que nos atraviesan en nuestros recorridos personales y profesionales. Estas experiencias nos (trans)forman y producimos memorias, aprendizajes colectivos y lecciones de vida que marcan nuestra marcha académica, señalándonos otras direcciones y posibilidades educativas.

En esa perspectiva, presentamos aquí una reflexión sobre la necesidad de cambios paradigmáticos en la matriz sociopedagógica de los procesos formativos de los futuros docentes, evidenciando algunos aspectos de una experiencia concreta realizada entre los años 2015 y 2019 en el interior de la Amazonia brasileña, en el ámbito del ya mencionado Proyecto Magisterio Extractivista. La metodología utilizada se caracteriza por la inmersión directa en el contexto de la experiencia aquí registrada, así como por la observación participante y por el análisis de esos registros.

Al trabajar la disciplina de educación infantil para jóvenes y adultos en el contexto de la Resex Río Iriri, teníamos la responsabilidad de materializar los principios educativos de la propuesta pedagógica del Proyecto, nosotros creemos y reivindicamos nuestras prácticas. La experiencia de 'ruptura' comienza en el puerto del río Xingu, en Altamira, pues el tiempo del viaje hasta la comunidad es, en promedio, diecisiete horas en barco, y el paisaje en el trayecto, marcado por una profusión de 
imágenes entre bosques, aguas caudalosas y cascadas, nos desafía a indagar sobre cómo sería ser niño, ser niña en un territorio extractivista, nos pusimos a pensar en esa visión, que tendrían libertad y la mejor infancia del mundo.

Después de ese largo trayecto, y algunas horas de descanso, al iniciar las clases, cumplidas las obligaciones protocolares, organizamos las sillas en círculo con un conjunto de juguetes en el suelo, encima de una pañoleta de colores, rodeados de libros de literatura infantil como: A vida secreta das formigas, O menino do dedo verde, O Bicho vai pegar, Cidade dos bichos; son lecturas que tratan de la relación con la naturaleza y los seres vivos.

Trabajamos también, películas y documentales que retratan la inteligencia atenta e inventiva de los niños como, Kiriku e a feiticeira, Tarja Branca y Território do Brincar, son documentales brasileños sobre la importancia de los juegos y de la cultura popular en la infancia y en la vida adulta. Conversamos sobre el material y presentamos los textos que iban a leer en la actividad, O brincar na Educação Infantil: transgressões e rebeldias; Relações entre as crianças pequenas e a produção das culturas infantis: vistas, ouvidas, citadas - material que fue cuidadosamente pensado para tejer correspondencias con el contexto de vida de aquellos estudiantes/futuros maestros, sus modos de producción cultural, sus prácticas de lenguaje y su relación con la naturaleza, en el sentido de comprender la concepción que tenían de la niñez y de la infancia en el territorio extractivista, en los ríos y en los bosques amazónicos.

En las actividades de ruedas de conversación, hubo relatos de la infancia, que no coincidieron siempre con nuestra visión previa de "paraíso", de felicidad junto a la naturaleza, traían registros de violación de derechos, de marcas del trabajo infantil, de violencias; pero, también, de afectos, de juegos colectivos en la selva y en el río, de aprendizaje práctico con sus padres y parientes de más edad. Fueron momentos propicios para una reflexión sobre la infancia y sobre el papel de la escuela en la vida de aquella comunidad, en el proceso de formación para la ciudadanía plena. Realizamos actividades de dibujos libres y muestras de las producciones de los alumnos.

En cuanto a las actividades con las películas y los documentales sobre el jugar, dialogamos sobre la importancia del acto de jugar tanto en la escuela como en otros espacios, considerando la temporalidad de las infancias conectadas con la naturaleza, con las estaciones del año, con los saberes tradicionales, con sus prácticas religiosas y las entidades sagradas de las aguas y de los bosques. Así, reflexionamos sobre los saberes presentes en los colores, en las formas de pintar, en la coordinación motora, sobre los aspectos cognitivos y subjetivos que una actividad de pintar puede revelar, elementos que involucran sentimientos, como tristeza, alegría, timidez, curiosidad, libertad de transitar y de aventurarse por las cascadas de los ríos entre las piedras.

En ese proceso de producción de conocimientos, observamos que los estudiantes comenzaban a tener posturas de mayor autonomía, de alteridad y autoría, al ser tomados como sujetos socioculturales; ejercitamos el quiebre del endurecimiento impuesto en los contenidos del currículo prescrito y sin vida. Y de esta forma, las actividades se desbordaron de aprendizajes, significados y sentidos, dada la riqueza de los intercambios de experiencias y saberes impresos en la oralidad y en todas las formas de expresión de lenguajes, como producción de poesías, dibujos, materiales didácticos, saraos, teatros y juegos. 
También hubo actividades culturales, organizadas por los alumnos con la participación de la comunidad local, las cuales mostraban marcas de la cultura indígena y ribereña, memoria e historias ancestrales sagradas, en forma de danzas y canciones. En ese momento colectivo abierto a la comunidad, los estudiantes presentaron sus producciones: juguetes hechos de paja, arcilla, madera, tejido etc. entrelazados a sus infancias, como ilustran las figuras a continuación.

\section{Figuras 1 y 2:}

\section{Juguetes confeccionados por los alumnos}
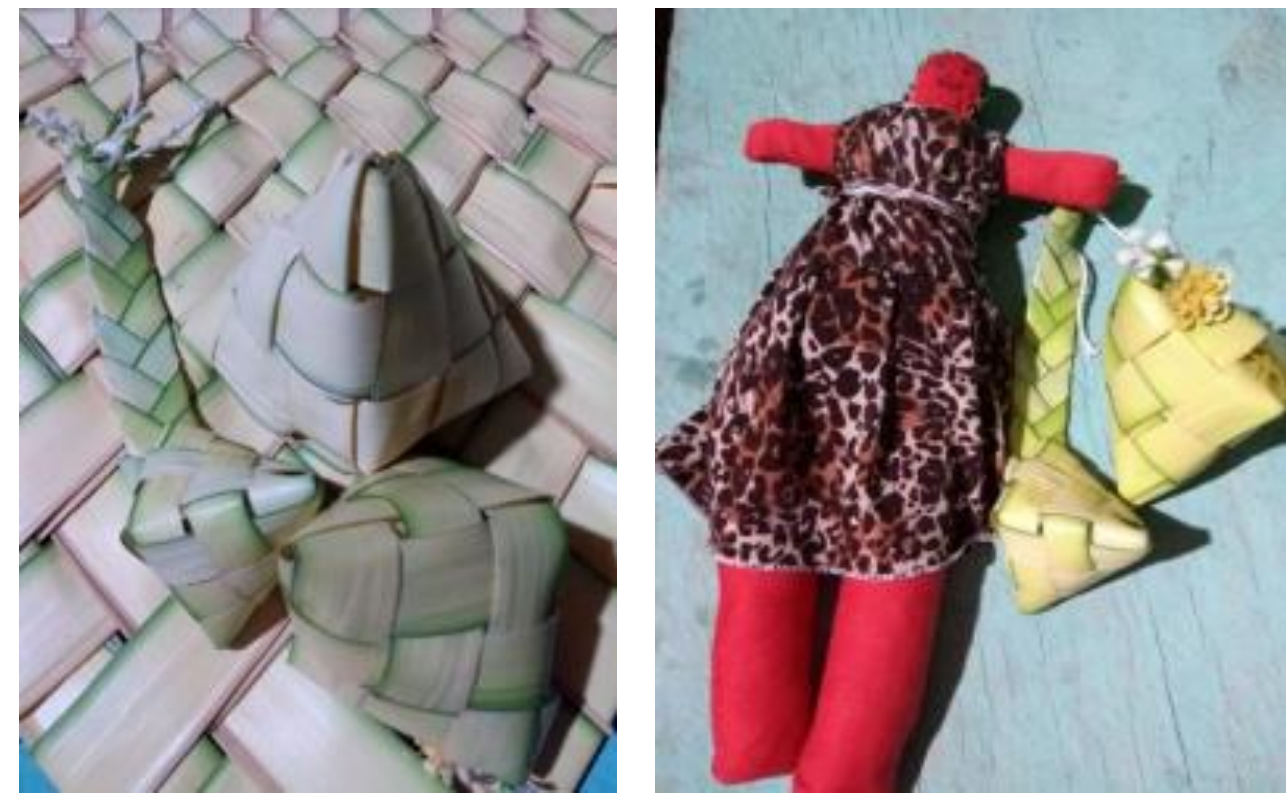

Fuente: Archivo de las autoras, 2018.

Estas imágenes expresan arte, lenguaje y un conjunto complejo de saberes culturales locales, heredados de sus antepasados: la artesanía de los tejidos, la confección de instrumentos de trabajo, como paneros, cestos, cofos (cestos para el pescado), flandres (láminas de metal para hacer utensilios), esteras y muchos otros artefactos. En las actividades propuestas, los alumnos produjeron miniaturas de esos instrumentos de trabajo, porque forman parte del contexto de sus infancias, así como lo son los juguetes de arcilla y las muñecas de retazos de tela.

La narrativa pedagógica de esta experiencia se ha propuesto ser una práctica innovadora y diferenciada, que consideró el contexto de vivencia de los alumnos del Proyecto Magisterio Extractivista, en la búsqueda de esa mirada crítica y reflexiva en el proceso de formación de docentes, sobre esas concepciones prácticas desarrolladas en las guarderías y pre escuelas de comunidades tradicionales, así que, nuestro papel es instigar el deseo de cualificar la propuesta pedagógica para la educación y el cuidado de la primera infancia, sobre todo en áreas de conservación de la Amazonia. 
En la perspectiva de la formación integral del sujeto, defendemos que los currículos de la educación básica estén conectados con competencias y habilidades volcadas hacia la realidad local. Aunque tenemos críticas de BNCC, estamos acordes en que:

La Educación Básica debe tener como objetivo la formación y el desarrollo humano integral, lo que implica comprender su complejidad y la no linealidad de ese desarrollo, rompiendo con las visiones reduccionistas que privilegian o la dimensión intelectual (cognitiva), o la dimensión afectiva. Significa, también, asumir una visión plural, singular e integral del niño, del adolescente, del joven y del adulto [y anciano] - considerándolos como sujetos de aprendizaje - y promover una educación volcada a su acogida, reconocimiento y desarrollo pleno, en sus singularidades y diversidades. (Brasil, 2017, p. 14)

Al trabajar prácticas educativas interactivas, convidamos y reconocemos a los sujetos como productores de conocimientos escolares e históricos, percibimos que la relación con la naturaleza es una marca identitaria de los niños y de las niñas de las comunidades tradicionales, pues, cada vez más, queda a la vista la relación sustentable y afectiva creada a partir del contacto y de la propia manera de sobrellevarse con la naturaleza local, con sus enlaces ancestrales, con la conexión entre los seres encantados, sagrados y todas las formas de vida. Este conjunto complejo de relaciones puede y necesita estar entrelazado al currículo de la educación básica y especialmente de la educación infantil. Conforme preconiza la relación entre lo que es básico/común y lo que es diverso se retoma en el Artículo 26 de la LDB, que determina que los currículos de la Educación Infantil, de la Enseñanza Fundamental y de la Enseñanza Media deben tener base nacional común, que será complementada, en cada sistema de enseñanza y en cada establecimiento escolar, por una parte diversificada, exigida por las características regionales y locales de la sociedad, de la cultura, de la economía y de los educandos (Brasil, 1996).

Aunque esté determinado por la Constitución Ciudadana de 1988, en el capítulo dedicado a los Derechos Sociales, en el Artículo 7ํㅡㄴ los derechos de los trabajadores urbanos y rurales, además de otros que persiguen la mejoría de su condición social y en el Inciso XXV - la Asistencia gratuita a los hijos y dependientes desde el nacimiento hasta los seis años de edad en guarderías y pre escuelas (Brasil, 1988), la realidad de la educación en comunidades tradicionales aún no ha sido contemplada con la garantía de ese derecho en toda su amplitud, en la región de la Transamazónica y Xingu, la educación básica del campo y de las comunidades extractivistas está marcada por la "nucleación" y polarización de la enseñanza. La "nucleación" guarda profunda semejanza con las escuelas multi seriadas.

Después de seis años de la creación del documento "Educación infantil en el Campo: propuesta para la expansión de la política", producido por el Grupo de Trabajo Interinstitucional - GTI, instituido por la Ordenanza Interministerial número 6/2013, firmada por los Ministros de Estado de Educación, de Desarrollo Agrario y de Desarrollo Social y Combate al Hambre, sigue siendo necesario y urgente el diálogo intersectorial, realizar un estudio nacional sobre las condiciones reales de la oferta y la demanda de la educación infantil en los espacios rurales, especialmente en las áreas de conservación en el interior de la Amazonia, con el fin de subsidiar acciones gubernamentales, proponer alteraciones en la política de formación de maestros de la educación infantil atinentes a las especificidades de los territorios rurales. 
La naturaleza puede proporcionar una serie de juguetes y juegos, si la miramos atentamente. El trozo de una rama se puede transformar en una varita mágica y con la arena construir bellos castillos con vistas al río o al mar. El Estatuto del Niño y del Adolescente (ECA sigla en portugués), garantiza, en su artículo no 16 , que los/las niños/as tienen derecho a jugar, practicar deportes y divertirse.

Es derecho de todos/as niños/as residentes en las áreas rurales del país a ser consideradas en su diversidad poblacional - hijos/as de agricultores/as familiares, extractivistas, pescadores/as artesanales, ribereños/as, asentados/as y acampados/as de la reforma agraria, quilombolas, "caiçaras", pueblos de los bosques, de las aguas, entre otros - bien como en las especificidades de la educación en la franja etaria de 0 a 5 años y once meses de edad. (Brasil-MEC, 2014, p. 04)

Sabemos que jugar es un acto fundamental en el desarrollo cognitivo, social y afectivo de los niños. Es la manera como se relacionan y descubren el mundo a su alrededor. En el aula, a las niñas y a los niños se los puede convidar a volcar su imaginación en el acto de jugar y hacer juguetes, valorizando el acto de jugar como la fortaleza de lo humano, un espacio donde se elaboran un conjunto de juegos simbólicos por los que expresan situaciones reales de sus vidas, sus diversidades culturales y singularidades de sus historias de vida.

Esos principios son, si se coadunan con lo que defiende Carvalho (2020), sobre la pedagogía de(s)colonial, un quehacer que se coloca dentro y entre los ámbitos del ser y del conocer, empoderando sujetos y comunidades para buscarles posibilidades de crear un mundo verdaderamente humano, desafiando la colonialidad y exponiendo sus límites y perversidades.

El pensamiento decolonial en América Latina/Brasil nos puede ayudar a vislumbrar nuevas posibilidades en el campo educacional problematizando la centralidad de las familias en las políticas brasileñas de la actualidad volcadas hacia la desresponsabilización del Estado, a través de recortes en la educación, en la salud y en otros servicios sociales, transfiriendo costos de vuelta para la familia. Ese proyecto conservador y liberal afecta directamente los derechos sociales y la condición de los individuos en la sociedad, alcanzando de forma específica a los niños y a las niñas (Cooper, 2007).

Entendemos que la educación infantil escolar es un espacio estratégico de contraposición a ese proyecto neoliberal, pues a partir de ella es posible intervenir en las dinámicas de atención a los niños y a las niñas (y a la familia), siempre que esa intervención esté pautada por prácticas que tengan por objetivo difundir y consolidar saberes, problematizando creencias y discursos neoliberales y conservadores, pues la pedagogía que realiza este proyecto neoliberal y neoconservador es una pedagogía que produce cuerpos dóciles, sumisos y que mantienen las estructuras vigentes, es una pedagogía colonizadora.

Las pedagogías de(s)coloniales nos presentan la posibilidad de repensar la realidad y las estructuras de la educación. Carvalho (2020) afirma que las nuevas pedagogías luchan contra la colonialidad del Estado y del conocimiento moderno, cuestionando las relaciones sociales y las estructuras educacionales para iniciar la construcción de una nueva realidad. Este proceso se inicia a partir del conocimiento del contexto en que vivimos, comprendiendo que las relaciones que estructuran la 
sociedad son históricas, sociales y culturales porque la cuestión de la pedagogía está, en último análisis, entrelazada con esos elementos.

En nombre de un proyecto económico que concentra riqueza y que expolia a la mayoría de las personas, se están retirando derechos sociales. Pero, existe la posibilidad de una reconstrucción a partir de las movilizaciones sociales, colectivas y comunitarias. Los ejemplos de Chile y Bolivia nos traen esperanzas, ya que no se relacionan al acto de esperar, sino que se relacionan al acto de movilizarse, de actuar. La educación puede ser el espacio donde se inicia ese cambio, pues a partir de ella es posible movilizar la potencia de la infancia y de los niños y de las niñas.

Los niños y las niñas son potentes y múltiples, logran construir diversas realidades y tienen una mirada que difiere de la mirada de los adultos. Movilizar acciones educativas que potencialicen esa mirada, esa capacidad de construir algo nuevo, posibilita iniciar un proceso de crítica y de desconstrucción. Un proceso que hace que los niños y las niñas se tornen sujetos en las relaciones sociales y comunitarias.

Aunque sepamos del endurecimiento de la educación escolar, compartimos significados profundamente insurgentes, que nos reconectan a otras lógicas de comprensión del mundo, por las cuales es posible experimentar libertad en las vivencias con los niños y las niñas en la escuela, porque les permiten transitar a partir de su propia casa, su propio lenguaje, sus memorias, sus elecciones y, simultáneamente, les permiten reconocer cómo la opresión se retroalimenta al aparentar una "única verdad"; por eso nuestra pretensión es, sí, desafiar la lógica de la desigualdad epistémica y, así, interrumpir los discursos y prácticas hegemónicos en el campo de la educación, desde la educación infantil, sin amarras a referencias eurocéntricas (Carvalho, 2020).

Nos hemos alejado de esa orientación perversa de borrar y silenciar las singularidades propias de la infancia de cada niño, de cada niña en particular y buscamos estrategias acogedoras del derecho de elegir caminos comprometidos con otras lógicas de conocer, ser, sentir y hacer, en la perspectiva de legitimar otras posibilidades de hacer educación con las infancias, de vivir y existir con y a partir de ellas, de sus relaciones de pertenencia a sus territorios y comunidades tradicionales, reivindicando sus saberes y prácticas sociales en el contexto de sus vidas.

\section{Consideraciones Finales}

En esa perspectiva de 'humanizar' la educación escolar, especialmente en la atención a los niños y a las niñas, es que defendemos la idea de una pedagogía insumisa, a ser vivenciada desde la micropolítica educacional como espacio privilegiado de actuación/transgresión mediante "tácticas y estrategias" (Certeau, 2009) para la subversión de la pedagogía hegemónica. Es en esa dirección que inscribimos el empeño cognitivo, político y existencial de pensar/crear e implementar otro paradigma de formación docente, sin perder de vista que implica operar cierta dislocación en diferentes componentes de la cultura escolar y de los sistemas de enseñanza, a partir de una visión en red.

Traemos esa alerta porque no podemos descuidar la doble presión sufrida por toda propuesta pedagógica: la que viene de la estructura social más amplia y la ejercida por los meandros de los espacios intraescolares. No subestimamos el poder 
coercitivo del sistema social, cuyas heridas se reflejan en la escuela de manera innegable, coaccionando, corrompiendo y cosificando personas y microprocesos (Bourdieu \& Passeron, 1975), ni tampoco ignoramos "los límites de la educación" (Perrenoud, 2005, p.9), pero nos preguntamos si debe ser siempre así, si el resultado de toda acción escolar desemboca necesariamente en algún tipo de colonización del otro. Por deber profesional y por opción político-existencial, respondemos que no y nos implicamos en procesos de investigación acción que coadunan con deseos de transformación social y subjetiva.

Podemos afirmar que el Magisterio Extractivista de Terra do Meio consiste en una reinvención de la formación docente porque sus principios y sus resultados, apuntan de forma clara e inequívoca hacia una concepción de educación escolar profundamente vinculada a las necesidades del territorio y de los sujetos involucrados en la experiencia, entrelazada a la realidad de la vida, culturalmente sensible, pero académica y humanamente exigente, porque es problematizadora.

La formación de docentes se puede contraponer a la lógica de mercado inaugurando de forma práctica otra ética sociopedagógica enraizada en la realidad de las áreas de conservación y cuestionar profundamente la pedagogía hegemónica por medio de una nueva praxis articulada a la existencia material y simbólica de los sujetos extractivistas y de su entorno no humano.

La formación de docentes, articulada a las comunidades tradicionales en su compleja ecología de vivencias en que cultura y naturaleza se toman en su entera complejidad, puede contribuir para reinventar formas más humanizadas y menos predatorias al actuar y estar en el mundo.

Finalmente, la formación de docentes puede, como intentamos mostrar en este trabajo, especialmente en lo que concierne a la educación infantil, ser un baluarte en la construcción de sujetos nuevos más imaginativos, que no sean domesticados por la fuerza avasalladora del capital, apostando a la acogida de la diversidad, al cuidado educativo con los niños y las niñas y a la lucha por derechos como posibilidad de construir ahora un futuro mejor para todos.

\section{Referencias bibliográficas}

Alarcão, I. (1998). Formação continuada como instrumento de profissionalização docente. In: Veiga, Ilma P. (org.). Caminhos da profissionalização do magistério. Campinas: Papirus.

Alonso, M. (Org.). (1999). O trabalho docente. Teoria e prática. São Paulo: Pioneira.

Arroyo, M. (2017). Passageiros da noite. Do trabalho para a EJA, itinerários pelo direito a uma vida justa. Petrópolis, SP: Vozes.

Arroyo, M. (2012). Outros Sujeitos, Outras Pedagogias. Petrópolis, RJ: Vozes.

Barbosa, M. C. S. y Fernandes, S. B. (2013). Educación infantil y educación rural: un encuentro necesario para hacer realidad la justicia social con los niños pequeños que viven en las zonas rurales. Revista de reflexión y acción, Santa Cruz do Sul, 21, 299-315. DOI: http://dx.doi.org/10.17058/ rea.v0i0.3388. Recuperado de https://bit.ly/380AMtp

Bourdieu, P. \& Passeron, J.C. (1975). A Reprodução: elementos para uma teoria do sistema de ensino. Trad. de Reynaldo Bairão. Rio de Janeiro: Francisco Alves. 
Brasil. Lei no 9.985, de 18 de Julho de 2000. Regulamenta o artigo 225, § 1, incisos I, II, III e VII da Constituição Federal, institui o Sistema Nacional de Unidades de Conservação da Natureza e dá outras providências. Ministério do Meio Ambiente, Brasília. (10 de março de 2020). Recuperado de: http://www.planalto.gov.br/ccivil_03/Leis/L9985.htm.

Brasil. (1996). Lei de Diretrizes e Bases da Educação Nacional. Brasília.

Brasil. (1988). Constituição da República Federativa do Brasil. Brasília.

Brasil. (2014). Estatuto da Criança e do Adolescente. Brasília.

Brasil-MEC. (2014). Educación Infantil en el Campo: propuesta de ampliación de la política. Ministério de Educación. Brasilia. Recuperado de http://portal.mec.gov.br >docman> Agosto-2014-pdf

Brasil. (2017). Base Nacional Comum Curricular (BNCC). Educação é a Base. Brasília, MEC/CONSED/UNDIME.

Candau, V. M. (2011). Diferenças culturais, cotidiano escolar e práticas pedagógicas. Currículo sem Fronteiras, 11 (2), 240-255.

Carvalho, E.S.S.; Júnior, D.V. R. (et.al.) (2020) (orgs). Pedagogias de (s)coloniais: saberes e fazeres. Goiânia, Elson S.S. Carvalho.

Certeau, M. (2009). A invenção do cotidiano: artes do fazer. 16. ed. Petrópolis, RJ: Vozes.

Cooper, M. (2017). Family values: between neoliberalismo and the new social conservantismo. NY: Zone Books.

Clandinin, D. y Connelly. F. (2015). Pesquisa Narrativa: experiência e história em pesquisa qualitativa. 2. ed. Tradução do Grupo de Pesquisa Narrativa e Educação de Professores ILEEL/UFU; Uberlândia: MG: EDUFU

Freire, P. (1967). Educação como prática da liberdade. Rio de Janeiro: Paz e Terra.

Freire, P. (1996). Pedagogia da autonomia: saberes necessários à prática educativa / Paulo Freire. - São Paulo: Paz e Terra.

Freitas, A. (2007). Os desafios da formação de professores no século XXI: competências e solidariedade. In: Ferreira, Andrea Tereza Brito; Albuquerque, Eliana Borges Correia de; Leal, Telma Ferraz (orgs.). Formação continuada de professores. 1 ed., 2 reimp. Belo Horizonte: Autêntica.

Freitas, M. (2019). Realidade e desafios da educação infantil do campo na Amazônia paraense. Recuperado de https://periodicos.ufsc.br

Galzerani, M. (2013). Imagens que lampejam: contribuições de Walter Benjamin para a produção de conhecimentos históricos. Encuentro de Saberes. Luchas populares, resistencias y educación 53 (1).

Galzerani, M. (2008). A produção de saberes históricos escolares: o lugar das memórias. In: Ferreira, A. C. Ferreira; Bezerra, H. G.; de Luca, Tania Regina (Org.). O Historiador e seu Tempo. 1ed. São Paulo: EDUNESP.

Gatti, B. A. (2010). Formação de professores no Brasil: características e problemas. Revista Educação e Sociedade, 113 (31),1355-1379.

Gimonet, J. (2007). Praticar e compreender a pedagogia da alternância dos CEFFAs. Petrópolis, RJ: Vozes.

Lopes, R. et all. (2013). Relatório do Projeto de Pesquisa: Entre Preservação e Transformação: a influência da variável educação escolar nos modos de vida das comunidades tradicionais das reservas extrativistas da Terra do Meio no Pará, UFPA/PROPESP.

Nóvoa, A. (1995) (org.). Profissão professor. 2. ed. Porto: Porto Editora.

Nóvoa, A. (1999). O passado e o Presente dos professores. p. 13-34. In: Nóvoa, António. Profissão Professor. 2 ed. Porto: Porto Editora.

Parente, F., Lopes, R., y Miléo, I. de Oliveira (2020). Pedagogia da Alternância na Formação de Professores Extrativistas: uma Experiência na Terra do Meio, 
em Altamira/PA. Revista Humanidades e Inovação 7 (12), 63-77. Recuperado de: https://revista.unitins.br

Perrenoud, P. (2005). Escola e cidadania. O papel da escola na formação para a democracia. Porto Alegre: Artmed.

Pinho, V. (2016), (orgs.) Educação para a diversidade: experiências inovadoras na formação docente. Curitiba: Editora CRV.

Sarmento, M., y Tomás, C. (2020). A infância é um direito? Sociologia.15-30. DOI: https://doi.org/10.21747/08723419/soctem2020a1

Saviani, D. (2009). Formação de Professores: aspectos históricos e teóricos do problema no contexto brasileiro. Revista Brasileira de Educação, 40 (14).

Tavares, C. (2020). Educação em direitos humanos na educação básica: reflexões sobre sua prática pedagógica em escolas públicas. Revista Olhares, 02 (08).

Unesco. (2015). Programa Mundial para Educação em Direitos Humanos: terceira ase, plano de ação. Recuperado de https://unesdoc.unesco.org;

Velásquez, C., Boas, A. \& Schwartzman, S. (2006). Desafio para a gestão ambiental integrada em território de fronteira agrícola no oeste do Pará. Revista de Administração Pública, 40 (6), 1061-1075.

\section{Nota}

(i) The translation of the abstract and keywords in English was done by Suzanny da Silva Lima, Professor at Federal University of Pará (UFPA), Brazil. E-mail: suzannylima@ufpa.br. 